\title{
Understanding the development of organizations at the crossroads of the course of action and the instrumental approach: the transitional perspective
}

Appréhender le développement des organisations à la croisée du cours d'action et de l'approche instrumentale : la perspective transitionnelle

Anne Bationo-Tillon, Céline Poret and Viviane Folcher

\section{OpenEdition}

Journals

Electronic version

URL: https://journals.openedition.org/activites/5402

DOI: $10.4000 /$ activites.5402

ISSN: $1765-2723$

\section{Publisher}

ARPACT - Association Recherches et Pratiques sur les ACTivités

Electronic reference

Anne Bationo-Tillon, Céline Poret and Viviane Folcher, "Understanding the development of organizations at the crossroads of the course of action and the instrumental approach: the transitional perspective", Activités [Online], 17-2 | 2020, Online since 15 October 2020, connection on 25 August 2021. URL: http://journals.openedition.org/activites/5402 ; DOI: https://doi.org/10.4000/ activites.5402

This text was automatically generated on 25 August 2021. 


\section{Understanding the development of organizations at the crossroads of the course of action and the instrumental approach: the transitional perspective}

Appréhender le développement des organisations à la croisée du cours d'action et de l'approche instrumentale : la perspective transitionnelle

Anne Bationo-Tillon, Céline Poret and Viviane Folcher

\section{Introduction}

1 In this paper, we propose to address the question of possible conceptual ways of thinking about, studying and accompanying the development of organizations through transitional forms of individual and collective activities.

2 Supporting an organization to become something new means considering development as a gamble, the outcome of which is never known in advance (Folcher \& BationoTillon, 2018, 2019). We will begin by introducing the concept of boundaries and defining development as the crossing of boundaries. We will then explore transitional phenomena in more detail, in order to understand the singular development paths of individuals and groups of individuals. In seeking to interpret developmental forces, however, researchers come up against the following difficulty: subject's worlds ${ }^{1}$, groups, subjects and activity systems all evolve in concert. The well-established limits of these boundaries disappear as, in fact, it is the relationships between these entities that are transformed. The aim is therefore to acquire theoretical frameworks to understand what emerges from the intertwining of activity systems. The main thrust of the article will therefore consist in exposing the theoretical and empirical 
hybridization that we have carried out in two separate fields of research to understand transitional forms of activity that enable subjects and groups to create continuity between discontinuous activity systems. We will hence show in this article how we combined two conceptual approaches from the field of ergonomics: the course of action (Theureau, 2004) and the instrumental approach (Rabardel, 1995), to address developmental questions in order to shed light on the transitional instruments created by those involved in crossing boundaries. Lastly, we will discuss the potential contribution of this so-called transitional approach in thinking about organizations in the making.

\section{The development of organizations: boundary crossings made possible by transitional phenomena}

Development can be defined as the crossing of boundaries between two heterogenous activity systems (Akkerman \& Bakker, 2011). However, this way of describing development takes the point of view of an outside observer. What happens from the point of view of those involved in this boundary crossing? This is what we propose to study by means of the transitional perspective.

\subsection{Boundary crossing and the development of organizations}

According to Akkerman \& Bakker (2011), boundaries are functionally ambivalent, as they make it possible to link the different parts of a system, while at the same time dividing and separating them. Boundaries in this context are sociocultural differences that produce discontinuity in the actions and interactions of individuals and/or groups of individuals. These authors also examine people working at the boundaries, building bridges between worlds, practices and activity systems. These boundary-crossing individuals are confronted with the dialectic of the near and the far, as they act as bridges between separate worlds, while representing and incarnating the division between these relative worlds. They are considered both as essential links between diverse practices (Wenger, 1998), and as peripheral individuals, not really belonging to or participating in any community of practices.

5 Boundaries make it possible to set apart what is already established within an organization or community from what has not yet been developed. However, crossing boundaries within institutions means overcoming the contradictions that exist within the institutions themselves. In particular, this may consist in crossing boundaries between different forms of activity co-existing (Engestrom, 2001) within the organization. While business leaders are very focused on hyper-streamlining production processes in order to increase market share and thereby grow their businesses, we offer the hypothesis that an organization can also develop through the crossing of boundaries between different systems of work, even that abandoned areas exist within organizations that can be reclaimed with the crossing of internal boundaries within the organization. These boundary crossings can give rise to various forms of hybridization and crystallization. For Akkerman \& Bakker (2011), hybridization refers to a combination of ingredients from different worlds to create something new, which may take the form of new tools, new signs, new concepts, new practices and/or new collaborations. 
Crystallization, on the other hand, is the reification of experience. It may take the form of new routines or procedures making it possible to embody or render routine what has been created or learned. Boundaries and boundary crossing are malleable phenomena, as boundaries are not fixed once and for all, but emerge from an oscillation between the fusion of worlds and the dissolving of boundaries, and the rebuilding of boundaries and the impermeability of worlds. It is a dynamic phenomenon, which leads us to consider the concept of the boundary not only in terms of barriers, but as heuristic gateways for researchers and practitioners seeking to support an organization in the making.

7 The consideration of boundaries in analysis and intervention has led researchers to adopt ecological methods (Hutchins, 1995; Suchman, 1989), as well as broader units of analysis enabling them to interpret at least two interconnected activity systems. This is clearly the avenue taken by Engeström (2001) and Akkerman \& Bakker (2011). A second avenue of research consists in observing, examining and understanding the repair/ reconstitution/reassembly strategies and activities implemented by people working at the boundaries to deal with the fragmentations and discontinuities caused by the boundaries. This second avenue complements the first and sheds light on the organization in an intrinsic manner based on the activity of people working at the boundaries.

\subsection{Development of organizations and transitional dimensions of human activity}

8 What happens at the boundaries? How can we observe, examine and analyse the way in which people reconstitute units of activities fragmented by boundaries? In order to tackle these questions, we propose to examine in particular the transitional activity of people working at the boundaries, in order to understand how they forge continuity for themselves and their group(s). In other words, how do groups create boundaries to create intrinsic continuity and not lose their dynamism (Wenger, 1998). We will begin by specifying what we mean by a transitional approach. We will start by introducing the transitional phenomena as defined by Winnicott, then go on to explain how this enables us to address issues of continuity and discontinuity. To this end, we will take the example of the first empirical research into travel narratives, which marks the first foray into this transitional approach. This will also provide us with an opportunity to introduce the notion of transitional instruments.

\subsubsection{Winnicott's transitional phenomena}

9 In Playing and Reality, Winnicott (1971) proposes an ontogenesis of play situated in a space he calls either the 'potential space' or 'intermediate area of experience'. He introduces his work by pointing out the absence of conceptualization in the psychoanalytical field of an area, which nonetheless deserves attention and which he situates as lying between two realities: the personal inner reality and the outer, shared reality. He starts by describing transitional phenomena in infancy, from material collected over the course of his paediatric work, before moving on to make a more general proposal, claiming that the intermediate area is universal and persists throughout the individual's life (particularly in the fields of culture, art, religion, scientific creation, etc.). Hence, a child's comfort blanket or teddy bear is 
conceptualized by Winnicott as a transitional object, enabling the child to create, imagine, invent and endure their mother's absence via a symbolic extension. The presence of the transitional object helps the child to forge continuity in the absence of the mother: thanks to the transitional object, their mother is not completely absent, as the child is able to keep certain aspects of her close to them. The child knows, however, that the transitional object (blanket or teddy) does not fully replace their mother; the transitional object is a bridge, enabling the child to feel that an experience has not suddenly ceased. It enables the child to pass from the subjective to the objective. It marks the child's progress towards lived experience. Winnicott specifies that it is not the object itself that is transitional, but that this object represents the transition of the infant from a state of union with the mother to a state in which he or she has a relationship with her, as something external and separate. Winnicott thus points out that what is key to the transitional object is continuity for the subject.

This insight shows that materiality is not absent from these transitional phenomena. Hence, the intermediate area of experience has a function clearly identified by Winnicott that consists in maintaining the inner and outer realities both linked and separate.

'In the life of every human being exists the inner reality, the outer reality and a third part, the intermediate area of experience, to which both the inner life and outer life simultaneously contribute. This area exists as a place of rest for the individual engaged in the interminable human task that consists in maintaining inner reality and outer reality both separate and connected. The intermediate area is situated between the subjective and what is objectively perceived.'

11 How, then, does this intermediate area of experience make it possible to keep the inner and outer realities both separate and connected? While Winnicott does not list all the activities that take place in this intermediate area of experience, he does evoke some of them, such as dreaming, playing and therapeutic work, which is just one play activity among other. Hence, through reading Playing and Reality, we understand that this intermediate area of experience emerges where worlds intertwine: First between mother and baby, then between the child who becomes an adolescent and the family, and gradually between the individual and society, a long-distance boundary area between inner reality and outer reality. The subject can manipulate the multiple facets of his or her inner and outer reality via remodelled transitional objects in this inbetween zone. This process enables the subject to play freely with his or her capacity to duplicate, repair and connect different worlds or activity systems.

\subsubsection{At the origin of the transitional perspective: travel narratives \& transitional instruments}

The transitional perspective originated in research into the travel narrative field of activity, which we have been able to study at length (Bationo-Tillon, 2006, BationoTillon, Folcher \& Rabardel, 2010). As Nicolas Bouvier reminds us 'you think you are going on a journey, but soon it is the journey itself that makes and unmakes you', (Bouvier, 1992). Travel typically corresponds to episodes in life when experience depends on the manner in which the subject faces the test presented by the event: either the subject reduces the event to 'been there, done that', in which case the experience established itself as closed; or the subject faces up to the newness of the event, in which case an intermediate area of experience emerges, opening up a range of possibilities. In other words, constituted experiences imply closure, whereas open experiences imply 
movement and the emergence of transitional phenomena (Winnicott, 1971). This distinction between open and closed experience (Pastré, 2011) is reminiscent of the distinction drawn by Christin (2014) between the attitude of travellers and that of tourists. Hence, travellers prefers the journey to the destination and are open to discovery, unpredictability, experiences and encounters. They adopt an open attitude to themselves and to the world, and accept being disrupted and taken out of their normal routines. Tourists, on the other hand, close themselves off to experience. Nomadic writing (Christin, 2000) establishes a link between the here and now, as well as between the past, present and future. Travel writing therefore appears as an episode of indetermination offering the traveller and narrator the possibility of inventing other forms of connection to the world, the self and others: an episode of indetermination creating a link between the current traveller and the narrator in the making. We call this type of episode a 'transitional episode'. The transitional prism raises the following question: how does the narration of a transitional episode in the progress of taking place make it possible hold multiple realities both together and separate?

When we look at the diversity of people who travel and produce very diverse narratives (travel enthusiasts, ethnologists, journalists, etc.), despite the abundant variety (properties of the narratives, nature and duration of the journeys, purpose of the narratives, etc.), forms of invariance are at work via the fragments collected, assembled and developed over the course of the journey (Bationo-Tillon, 2006; 2010). The traveller returns, enriched by their experience and by these miscellaneous fragments collected/ developed in different space times of the journey. Upon their return, the traveller will spread out the scattered fragments and roam through them in order to recreate a world constituted by fragments of experience: a necessary condition for producing a travel narrative. Transitional phenomena enable the subject to maintain a link to their experience while at the same time objectivizing it and viewing it from an external point of view. The narration material is composed of heterogenous information collected, produced or captured while travelling. It therefore enables the narrator first of all to cut up and organize the flow of experience. This material then acts as mediator for the narrator, who revisits moments in the past and reimmerses himself or herself in the experience, in order to develop a narrative. It marks the progression towards lived experience and towards the distancing of the lived experience, while remaining essential for reimmersion into the same lived experience. This material thus constitutes transitional phenomena as understood by Winnicott. For this reason, we have identified and grouped together all these scattered fragments under the term 'transitional instruments', as clues to the narrator's ability to connect worlds and switch back and forth between the extraordinary world of travel and the ordinary and familiar world of the narrator, and as bridges enabling the narrator to feel that the experience did not suddenly cease.

'An instrument is transitional if it does not only contain the idea of mediation (already present in the definition of the instrument), but performs the role of a link, a transition between one situation and another spatiotemporal situation. An instrument becomes transitional from the moment a subject attributes to it the specific status of memory aid, witness or depositary of the traces of a lived experience. It is constituted, made and appropriated by the subject. It is transitional as the subject has it transit from one situation S (place, space, moment) to another situation s2. Its role in s2 is to refer to situation S1. The subject uses it in various activities discontinuous in time, i.e. in different activities anchored in different situations. They are instruments for distancing the experience at the time 
they are created, and instruments for immersing oneself in the past experience

when reused to develop a narrative.' (Bationo Tillon, Folcher \& Rabardel, 2010)

(Bationo-Tillon, 2010), we have identified cooperative transitional instruments (Poret, 2015) that redesign the boundaries within organizations. We have shown (Poret, 2015; Motté \& Poret, 2018) how current information systems (IS) not only fragment the activity of operators, but prevent them from reconstituting the continuity necessary for the successful performance of their activities. They therefore cobble together transitional instruments by diverting the functions of the IS in order to reforge fragmented units of activities. Through the intermediary of cooperative transitional instruments, operators therefore reconfigure the boundaries. They render certain boundaries more permeable in order to make a cross-sectional collective activity more efficient (Motté \& Haradji, 2010). We will show that the transitional thread is therefore also applied in organizations, by means of a second area of study concerning the commercial customer relationship process, in the context of the processing of requests for a 'dual-fuel' connection (Poret, 2015; Poret \& al, 2016).

\section{A necessary conceptual hybridization to approach transitional instruments}

17 Considering the question of transitional activity as an activity in the process of emerging in the world, reconciling multiple systems of rationality and activity, seems particularly heuristic to us. This perspective invites us, on the one hand, to consider the gestation of activity along the lines of the proponents of enactivism (Varela \& Maturana, 1972; Theureau, 2004) in order to bear in mind how activities emerge in the world. On the other hand, this perspective led us to apply the notion of transitional 
instrument in two studies in very different fields of activity, but whose comparison seemed to us to offer fertile ground for thinking about organizations in the making. In particular, in order to exemplify the implementation of the conceptual hybridization necessary for the transitional perspective, we will set out in detail the two research studies in question, i.e. the study of travel and the study of the commercial customer relationship process.

\subsection{Hybridization of the instrumental approach and course of action}

In order to highlight the existence of transitional instruments, we had to adapt our conceptual and methodological tools for collecting and analysing data. Transitional instruments help us to better understand what appear to be ruptures from an extrinsic point of view and which, however, paradoxically reveal deeper, more intimate continuities from an intrinsic point of view. In order to understand the diachronic progression of discontinuous activities, we used the course of action (Theureau, 2004) and the instrumental approach (Rabardel, 1995) in a complementary manner. These two approaches enable us to switch back and forth between a singular and generic description and understanding of discontinuous activities, and also to explore their different temporalities (synchronic and diachronic scales).

This led us to explore other ways of approaching diachrony in the implementation of the instrumental approach, as it meant studying different activities in different situations. The unit of analysis usually proposed by the instrumental approach is the instrumented activity situation. The object of the activity, relatively stable over time, takes into account the finalized dimension of the situated activity. In effect, the notion of situation is key and Rabardel (2001) specifies that any instrumented activity is always situated and finalized. Hence, the quadripolar model (see Figure 2), which lies at the heart of the instrumental approach, always refers to a situation and to a relatively stable object of the activity. This framework therefore invites us to dissect what is real, by identifying the poles and the structure of the activity (subjects-instrument-object of the activity).

Figure 1: Quadripolar model of instrumented activity situations. Figure 1 : Modèle quadripolaire des situations d'activité instrumentée

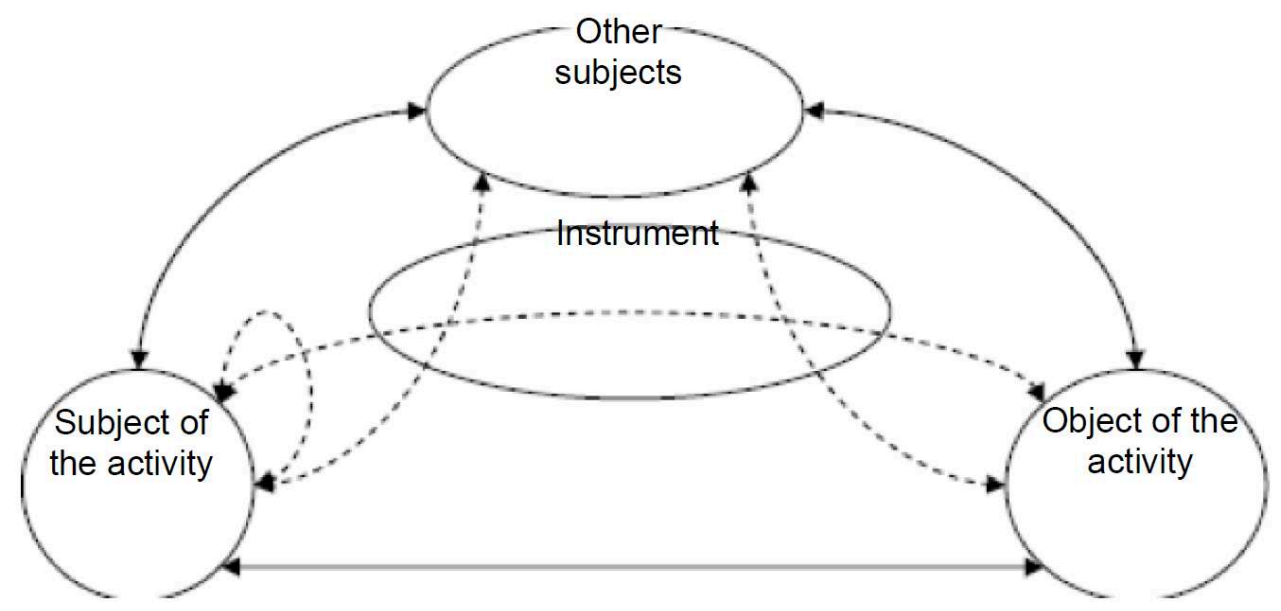

Through its concepts, therefore, the instrumental approach enables us to interpret structural and functional continuities through the invariant organization of the 
activity focusing on an object of the activity. We therefore sought other avenues than the stability of the object of the activity to implement the instrumental approach diachronically.

21 To explore this alternative avenue, we use the course of action, as by precisely documenting the point of the view of the agent at each moment through a phenomenology of human activity, the course of action (Theureau, 2004) enables us to describe the construction of the experience. The course of action (Theureau, 2004, 2006) also provides a heuristic theoretical framework for addressing the volatility and successive times of discontinuous activity. It makes it possible to maintain the various histories concomitant to the activities in which the subject is involved, possible solely by remaining as close as possible to the singular course of experience.

However, documenting the invariants of the narrative activity in its diachrony leads us away from following the course of action methodology in a strict sense, as we follow the methodology for constructing a reduced narrative without exploring further the possibilities offered by the decomposition of the hexadic signs.

It is these conceptual hybridizations and methodological constructions necessary for shedding light on transitional instruments that we will describe in more detail for each of the studies.

\subsection{Hybridization implemented via a succession of stages}

In this part we will present a succession of stages implemented in both fields presented in more detail in the rest of this paper. This is the result of a comparison between the methodologies used in each field to consider the transitional activities. We will describe each stage more fully for each field in the corresponding sections.

First, we made audio-video recordings of the activities, followed by self-confrontation interviews (Theureau, 2004). We also collected the traces of these activities (notebooks, files, log books, narratives and entries in the information system).

Next, once we had collected the empirical material, we coded then analysed these data in four stages ${ }^{2}$

- Development of reduced narratives: First, we used the course of action reading grid to describe the temporal process of the narrative activity according to significant units for the agent. The course of action (Theureau, 2004, 2006) makes it possible to rework and reorganize chronological time to constitute the agent's significant elementary units (S.E.U.). These S.E.U. correspond to the agent's actions, interpretations, focuses, emotions or communications. They emerge thanks to the description articulating the point of view of the observing researcher (extrinsic description) and the agent's own point of view (intrinsic description). The reduced narrative is composed by the chronological sequencing of the S.E.U.

- Constitution of classes of situations: Second, we used the instrumental approach to segment the process of the activities (in other words, the reduced narratives) by extracting instrumented activity situations in which we then identified schemes and instruments.

- Diachronic compilation: Thirdly, we accumulated layers of instrumented activity from different timeframes: T0/T1/T2/...Tn. This accumulation stage was necessary to understand the manner in which the instrumented activities sedimented over time. We were seeking to understand how traces of the activity reify at different moments in time: in other words, 
how they successively sediment and transform through the accumulation of temporal layers within heterogenous activity systems.

- Identification of transitional instruments: For this fourth operation, we rely on the reversibility made possible by a posteriori analysis, as we start from the finished form of the trace of the instrumented activity (a fragment of the final narrative, for example), and work back in an archaeological fashion through successive versions of the traces of the instrumented activity in order to understand what happened. Based on this, we deduct the transitional forms of the activity through the remodellings carried out by the subject, which transform not only the traces (visible dimension) but also and above all the subject's experience (invisible dimension).

\section{A conceptual hybridization making it possible to cross different levels of boundaries}

In the empirical part of this article, we will show the way in which transitional instruments are brought to light thanks to the hybridization of the instrumental approach and the course of action, through two studies heterogenous from the point of view of their temporalities, their fields of activity, their purposes and their depths of analysis.

\subsection{Travel writing}

While travel writing takes place for a subject already involved in the intertwining of worlds, it necessarily contributes to the percolation of these worlds. How do these worlds mix and overlap in concrete terms? What emerges from this percolation of worlds? This is what we aim to discover by studying the material traces of narrative activities, as clues or witnesses as to what takes place. The transitional prism raises a series of questions: What is the nature of the involvement of the traveller and narrator? How does the narration of the journey taking place make it possible hold multiple realities both together and separate? Let us first point out that we consider writing in a broad sense. Like Brunner (1990), we consider narration as a form of expression and a way of thinking that enables humans to construct interpretations of the world and give meaning to their experiences in order to share them with others. In this paper, we limit narrative activities to accounts of lived events and we include all artefacts (photographs, videos, drawings, writing, etc.) that may be articulated in the course of producing an account. We study both the collection activities throughout the journey (taking of photographs and notes, etc.) and the formatting activities giving coherence to the collected materials after the journey. In other words, we study narration in the making, i.e. the emergence of the meaning of the experience taking place for a varied panel of traveller narrators: two polar explorers and 10 other people with various profiles (journalists, ethnologists and bloggers). Video recordings were made ${ }^{3}$, partly to document the temporal and dynamic aspect of the narrative activity and also so that the researcher was not in the presence of the subjects or even an observer of the activities in real time. Subjective resitu interviews (Rix \& Biache, 2004) and selfconfrontation interviews based on traces of the activity were conducted a posteriori. These interviews were conducted based on a common questioning approach, focusing on questions concerning the subject's preoccupations and those factors to which they 
paid attention, as well as on the explanation of the actions taken (Theureau, 2004; Vermersch, 1994).

\subsubsection{Preparation of reduced narratives}

As the table below shows, we first applied the conceptual and methodological approach of the course of action. After transcribing all the self-confrontation interviews and coding all the video recordings, we put together the reduced narratives according to Theureau (2004) by merging and matching two flows of code: namely an objective/ extrinsic and chronological description of the activity (first five columns of the table below) and an intrinsic description of what is taking place for the agent, step by step, from the transcription of the self-confrontation (6th column in Table 1 below).

Table 1: Coding and transcription.

Tableau 1 : Codage et transcription

\begin{tabular}{|c|c|c|c|c|c|}
\hline time & $\begin{array}{l}\text { Work } \\
\text { space }\end{array}$ & Action of the subject & $\begin{array}{l}\text { Environm } \\
\text { ent }\end{array}$ & $\begin{array}{l}\text { Content of the } \\
\text { recording }\end{array}$ & \multirow{3}{*}{$\begin{array}{l}00: 04: 00 \text { As } P 2 \text { has bought this watch, there we are trying } \\
\text { to figure out how it works. It is an expedition watch, I set it } \\
\text { (altimeter, thermometer, time, compass, etc.)... So there } \\
\text { we are still trying to figure out how this electronic compass } \\
\text { works. } \\
00: 05: 00 \text { At this point do you start to write? }\end{array}$} \\
\hline \multirow[t]{2}{*}{$00: 04: 10$} & & $\begin{array}{l}\mathrm{P} 1 \text { looks at their } \\
\text { watch and states the } \\
\text { altitude to P2 }\end{array}$ & $\begin{array}{l}\text { P2 asks } \\
\text { P1 for } \\
\text { the }\end{array}$ & & \\
\hline & & & & & \\
\hline $00: 05: 03$ & & $\begin{array}{l}\text { Moves their pen close } \\
\text { to the notebook }\end{array}$ & & & \multirow{3}{*}{$\begin{array}{l}\text { Wait, I haven't started yet. So now I hesitate (I start on } \\
\text { the left or on the right) because I don't like starting on the } \\
\text { left like that. } \\
\text { In the end you start on the left, and you write LME } \\
\text { programme report? } \\
\text { Yes, in fact as it's not the time, I can put it on the left-hand } \\
\text { page and then I'll start the time on the right-hand page; I } \\
\text { thought about it during the day and I want to make it clear, } \\
\text { it's always important to get it down in black and white } \\
00: 06: 00 \text { Do you write in the form of a list? } \\
\text { Yes, there are some things which I want to pay attention } \\
\text { to. Er... so here it's a case of framing the agents' general } \\
\text { and singular issues, finding a balance, after a problem }\end{array}$} \\
\hline 10 $00: 05$ & |anoto & $\begin{array}{l}\text { Starts to write on the } \\
\text { left-hand page and he } \\
\text { underlines the text }\end{array}$ & & $\begin{array}{l}\text { 'LME programme } \\
\text { report' }\end{array}$ & \\
\hline 28 $00: 05$ & anoto & $\begin{array}{l}\text { He starts a new line } \\
\text { and writes }\end{array}$ & & $\begin{array}{l}- \text { framing of the } \\
\text { issues. " General } \\
\text { issues and } \\
\text { singular issues }\end{array}$ & \\
\hline
\end{tabular}

The merging of these elements enabled us to produce reduced narratives composed of significant elementary units. We did not decompose each of these units into tetradic or hexadic signs ${ }^{4}$ (Theureau, 2004), however, we documented for each S.E.U. the object of the tetradic sign ${ }^{5}$ (the preoccupation for the agent).

Table 2: Reduced narrative and objects.

Tableau 2 : Récits réduits et objets

\begin{tabular}{|c|c|c|}
\hline time & Occurrence of S.E.U. & objects \\
\hline $00: 05: 03$ & $\begin{array}{l}7 \text {-looks at anoto, hesitating whether to begin on the right or } \\
\text { on the left }\end{array}$ & \multirow[t]{8}{*}{$\begin{array}{l}\text { Keeping a trace of pragmatic } \\
\text { thoughts (things to do) }\end{array}$} \\
\hline $00: 05: 11$ & $\begin{array}{l}\text { 8-writes, naming the future list (on the left-hand page) LME } \\
\text { programme report and underlines }\end{array}$ & \\
\hline \multirow[t]{2}{*}{$00: 05: 26$} & 9-writes, drawing a dot & \\
\hline & 10-writes, listing a first idea & \\
\hline \multirow[t]{2}{*}{$00: 05: 58$} & 11-writes, drawing a dot & \\
\hline & 12-writes, listing a second idea & \\
\hline \multirow[t]{2}{*}{$00: 06: 03$} & 13-writes, drawing a dot & \\
\hline & 14-writes, listing a third idea & \\
\hline $00: 06: 20$ & 15-raises head & \multirow{2}{*}{$\begin{array}{l}\text { (other) Interacting with the } \\
\text { environment }\end{array}$} \\
\hline $00: 06: 22$ & $\begin{array}{l}\text { 16-discusses with } P \text { and } G \text {, talking to them about a map to } \\
\text { send to LME members }\end{array}$ & \\
\hline
\end{tabular}

31 Hence, the course of action enables us to separate a particular activity thread from the environment in which it takes place, without losing sight of the situated dimension, as the activity is understood in the conceptual framework as emerging in the step-by-step 
interaction between the subject and the environment. By producing these reduced narratives, we used the phenomenological course of action approach to unravel the narrative activities from the other activities with which they overlap, particularly in the course of the journey.

\subsubsection{Constitution of situation classes}

Secondly, we conducted an operation that consisted in chopping up the reduced narratives and translating them into situation classes. Given the volatility of the narrative activities, we use the objects of the triadic sign/preoccupation of the course of action as a basis for chopping up the reduced narratives and constituting instrumented narrative activity classes. Whereas in activity theories, the object of the activity does not change over time, in our context, the course of action enables us to identify the objects emerging step by step. A posteriori analysis therefore enables us to group together all the S.E.U. attached to the same object into situation classes, in order to then identify the schemes and instruments within these classes. Thus, based on Table 2, an instrumented situation class emerges entitled 'Keeping a trace of pragmatic thoughts'. This situation class enabled us to group together all series and sequences attached to this object, in order to then extract the invariants (scheme and/or instruments) ( for more details, see Bationo-Tillon, 2006).

A third stage then enabled us to include diachrony in the analysis, as shown in the diagram below based on the research carried out with two polar explorers:

Figure 2: Synchronic and diachronic analysis.

Figure 2 : Analyse synchronique et diachronique

\section{(T2) During the expedition (mobile}

\section{narrative activity)}

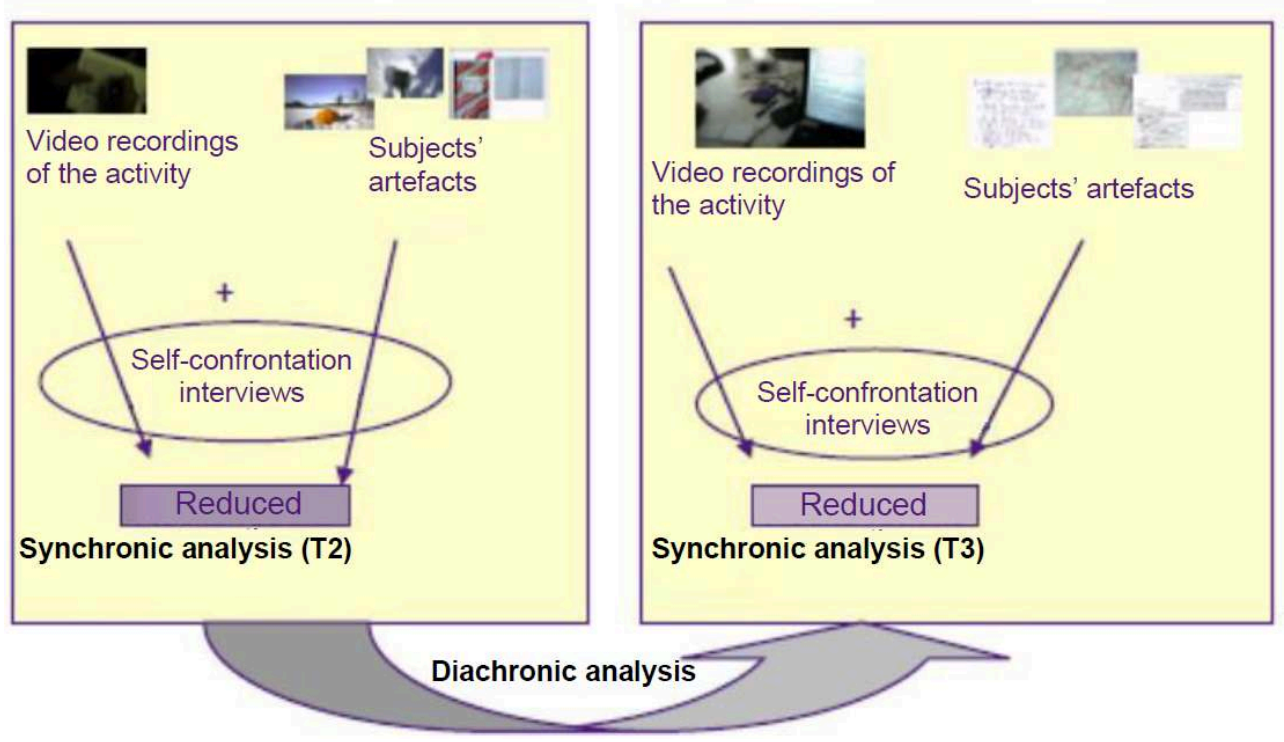

After the expedition (T3) (post-mobile narrative activity)

\subsubsection{Diachronic compilation}

Over the course of this stage, the researcher intervenes by compiling moments of activity to access the diachronic scale (T2/T3), by associating episodes of activity that do not have the same object but which are episodes of activity presenting continuity 
from the point of view of the materiality of the traces. These are the traces created in T2, which are taken up again and transformed in T3. This therefore constitutes more of a semiological continuity (continuity of the representamen ${ }^{6}$ ) and material continuity that a continuity of the object of the activity, as the object of the activity is transformed along the way. The instrumental approach therefore enables us to describe the differences in status of the fragments collected in $\mathrm{T} 2$ and $\mathrm{T} 3$, while the course of action enables us to identify the semiological continuities and discontinuities at work. Thus, the collected fragments constitute clues as to the meaning for the subject and encapsulate the meaning for the subject at a given moment: in another context, the subjects reuse and rearrange these collected elements in larger works (in the form of a specific narrative: the expedition log book for the community of polar explorers, for example), recomposing and reconfiguring the meaning of their experience, sometimes in a manner very different from how they would proceed to produce a scientific paper, for example. Hence, the diachronic scale is established by the intervening researcher, who chooses to focus on the development of one of the narrator's narratives. In doing so, the researcher accumulates the subjects' narrative activity at different times/places of the journey and documents the manner in which the narrator crosses the boundaries of worlds, by cobbling together continuity for himself while producing a specific account, as shown in the illustration below:

Table 3: The diversity of traces of narrative activity at successive times.

Tableau 3: La diversité des traces de l'activité narratives dans des temps successifs

\begin{tabular}{|c|c|c|c|c|c|}
\hline $\begin{array}{l}\text { T2 (during the } \\
\text { journey)/heterogeneity } \\
\text { of the narrative traces: } \\
\text { notes/videos/photos }\end{array}$ & 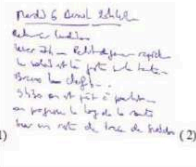 & 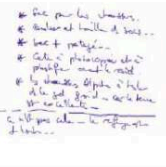 & 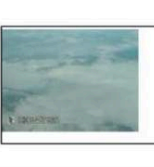 & atim & iniman \\
\hline $\begin{array}{l}\text { T3 (upon return from } \\
\text { travel)/narrative } \\
\text { developed by the } \\
\text { narrator upon their } \\
\text { return- } 3 / 12 \text { pages of } \\
\text { the log book } \\
\text { addressed to the } \\
\text { explorer community }\end{array}$ & & 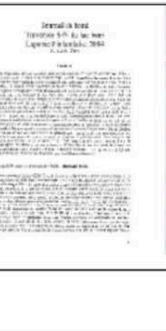 & 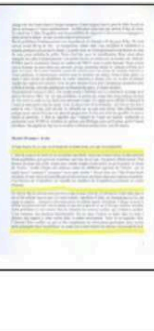 & 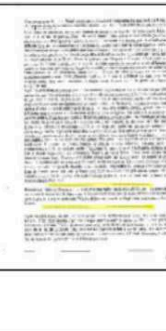 & \\
\hline
\end{tabular}

Hence, the researcher has accumulated a posteriori all moments and all narrative traces contributing to the production of the log book destined for the explorer community. It is the accumulation of these heterogenous activities guided by the traces of the narrative activity contributing to the production of this final document for the explorer community that makes it possible to introduce diachrony into the analysis.

\subsubsection{Transitional instruments}

In this fourth stage, the researcher identifies the narrator's semiological and material reworkings within the accumulated activities. In this ultimate stage of the analysis, the aim is therefore to combine the scales of the course of action and the instrumental approach, by combining the material reworkings (hence, by examining the material transformation of the narration materials) and semiological reworkings (the transformation of the meaning in another context, the manner in which new meaning 
is forged and transformed, or the manner in which continuity of meaning is forged for the subject). In this stage, the aim for the researcher is therefore to spread out the accumulated traces (texts, notes, fragments, photos, etc.) of the instrumented narrative activity, respecting the time course, in order to consider these traces as clues as to what emerges from the intertwining between worlds and as to the remodelling of subjects' experience taking place within the narrative activities. This enables us at this stage to perceive the various forms of diachronic narrative activity revealed by the transitional instruments, namely linear activities that tend to reuse content in an identical manner, as illustrated in this example of a mirror transitional instrument revealed in the activity of one of the explorers in Table 4:

Table 4: Mirror transitional instrument.

Tableau 4 : Instrument transitionnel miroir

\begin{tabular}{|l|l|l|}
\hline Written log book (T2) & $\frac{\text { Tuesday 30 March }}{\downarrow}$ & $\begin{array}{l}\text { Tuesday 6 April } \\
\downarrow\end{array}$ \\
\cline { 2 - 3 } Final document (T3) & $\begin{array}{l}\text { Tuesday 30 March } \\
\text { Blablablablablablabla } \\
\text { Blablablablablablabla }\end{array}$ & $\begin{array}{l}\text { Tuesday 6 April } \\
\text { Blablablablablabalablabala } \\
\text { Blablabalabalabalablabalabla }\end{array}$ \\
\hline
\end{tabular}

Transitional instruments can reveal filtering activities that consist in reducing and summarizing, as revealed by pragmatic transitional instruments, which are notes for action to be taken produced in T2 and which disappear in the final narrative in T3 (see Table 2).

Transitional instruments can reveal circular activities that consist in enriching the narration. For example, cumulative transitional instruments can provide a guiding thread for the narration. These can be instruments used during the course of the preparation of the narrative to summarize the various diegetic levels and in particular the relationship between elements drawn from specific observational circumstances (when the narrator reworks elements collected) and general statements of knowledge (when the narrator reworks formal information that may be taken from a dictionary or encyclopaedia).

We find that more or less time and space is taken up by the transformation activity at the time of preparing the narrative according to the type of transitional instruments.

Lastly, transitional instruments also reveal that successive and infinite reworkings are possible, exploring the depths of experience, through a reversible chain of experience composed of trans-contextual links overlaying worlds like Russian dolls. This brings us to the polyvocal and poly-addressee nature of transitional instruments. In effect, the same content can be instrumentalized differently over time and feed into successive and very different narratives.

\subsection{Cooperation in a commercial process}

41 The organizational forms that fragment communal production into different activities have become general practice over the course of the last few decades. While this fragmentation may be linked to the need for specific skills, it can also be the result of a refocusing by firms on their 'core business', leading them to externalize other activities to supply-chain-type networks of companies. Currently, within these organizational forms, cooperation is a key challenge. Cooperation within processes and supply chains 
is sought in particular through Supply Chain Management, one of the main objectives of which lies in 'integration', a notion used to describe the more cooperative nature and intensity of relations within a supply chain (Fawcett \& Magnan, 2002). Customersupplier contractual relationships are also tending to be more collaborative (Brulhart \& Favoreu, 2006). Despite this push for cooperation in order to break down the 'silos' created as a result of fragmentation, at a time when cross-sectionality is lauded as essential in every company, it is clear that decompartmentalization has not yet been fully achieved (Poret \& al, 2017).

The transitional perspective enables us to overcome this impasse and understand cooperation in an intrinsic fashion, as forming part of human activity. In the fragmentation clear in the activities carried out in the commercial process that we studied, a cross-sectional collective activity develops (Motté \& Haradji, 2010; Poret, 2015), originating in the people involved in the process, who link stages in the process together between them and maintain continuity in the collective processing of the customer's request despite the discontinuity characterizing the process. Through their transitional activities, they cross the temporal and spatial boundaries of the process, rendering the process efficient and ensuring customer satisfaction.

The aim here is to understand the way in which the agents forge continuity not between themselves in the here and now and themselves at a later time, as may be the case for the travel narrator, but between themselves in the here and now and other agents at a later time: those who will be responsible for taking over the processing of the customer's request subsequently. Contrary to the transitional thread that can be established for travel narrators, a significant difference therefore exists in this case: the discontinuity of the experience. The agent who collects scattered fragments at a particular moment is not the same as the agent who will have to rearrange them; these fragments are not fragments of experience for the agent responsible for taking over the processing of the customer's request. 
Figure 3 - The constituent stages of processing requests for dual-fuel connection.

Figure 3 : Les étapes constitutives du processus de traitement de la demande de mise en service biénergie

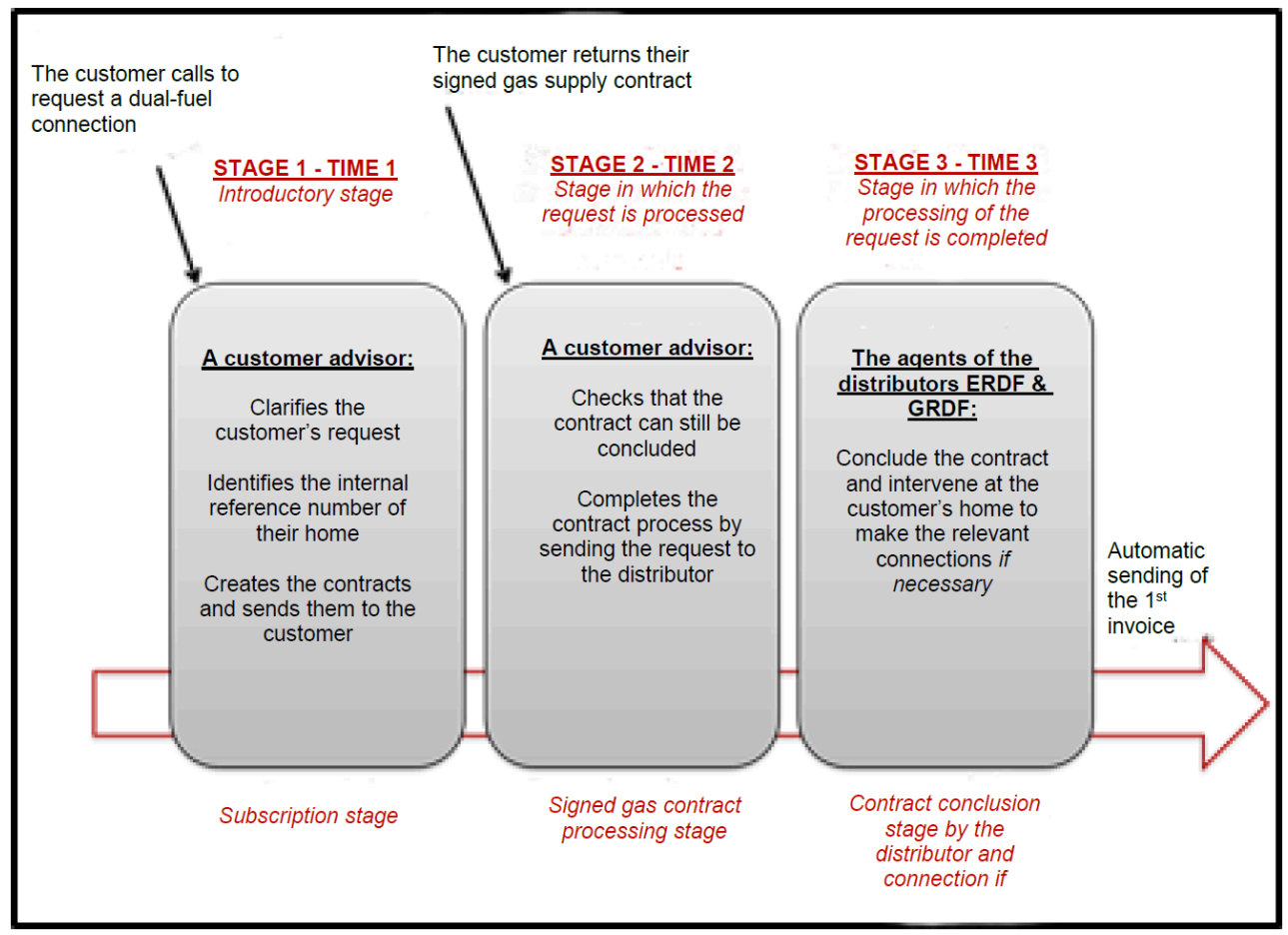

In order to ensure the customer's request is processed from beginning to end, this process necessarily includes several stages (Fig. 1), which are processed by different agents, within and outside the firm. This process is characterized by a temporal and spatial distribution of the contributions of the various agents, who must collectively construct the response to the customer's request despite this fragmentation.

The cross-sectional collective activity within this process takes the form of transitional activities that make it possible to maintain temporal continuity and ensure a progressive processing of the customer's request. At each stage in the process, the customer advisors:

- Need to understand the processing history of the request up to that point. To this end, they conduct a historical search to plot the traces left by previous agents in the processing of the request;

- Implement what they need to do at the current stage, so that the processing of the request can continue;

- Transmit and/or archive details concerning the stage they have just processed. They leave these details in the information system for the attention of those taking over from them in processing the request, elsewhere or later.

The general structure that we proposed consisted in starting from a phenomenology of the human activity, via the modelling of the history of the transformations of the system of openings ${ }^{7}$ at a particular moment $t$, and to gradually bring to light the cooperative transitional instruments. This structure hinged on the point of view of the agent and on the notions forming the basis of this point of view in each of the approaches. 


\subsubsection{Development of reduced narratives concerning each stage of the process} activity of the customer advisors involved in processing the various stages of the request for the dual-fuel service. We sat next to the customer advisor, with the camera focused on their computer screen, and took notes on their activity as well as on the verbalisations of the customer, who was also on the line. Directly after the stage was processed by the customer advisor, we debriefed them about what they had just done, in the form of 'case post-processing' interviews, which had the same objective as selfconfrontation interviews, i.e. the expression of the agent's pre-reflective conscience (Theureau, 2004, 2006). The specific nature of the collective activity considered as part of this work led us to assign a second objective to these interviews: debriefing the agents on the situation before and after their own contribution, to enable us to situate this contribution more broadly in the continuity of the processing of the request. In all, we collected 95 hours of audio-video recordings, from 24 customer advisors and 2 of their direct line managers. We will now set out in more precise detail the various stages of the hybridization between the instrumental approach and the course of action that enabled us to bring to light the cooperative transitional instruments.

We produced the reduced narratives based on 'chronicals', which correspond to a transcription of our data in the form of a table with several columns containing the observable behaviour and IT actions of the agents, the simultaneous verbalisations and verbalisations during self-confrontation. Our reduced narratives highlighted sequences - both continuous and discontinuous -, macro-sequences, series and synchrones, as well as the opening forming the basis of these significant units at each instant (Table 5). 
Table 5: Identification of significant elementary units of higher rank and of the opening on which they are based at all times.

Tableau 5 : Identification des unités élémentaires significatives de rang plus élevé et de l'ouvert qui les fonde à chaque instant

\begin{tabular}{|c|c|c|c|c|}
\hline $\begin{array}{l}\text { Significant Elementary Units } \\
\text { (SEU) }\end{array}$ & Sequences & Series & Macro-Sequences & Opening \\
\hline $\begin{array}{l}\text { SEU } 1 \text { 'Decide not to select } \\
\text { the DAT as a Customer } \\
\text { Advisor has already } \\
\text { intervened and changed the } \\
\text { date to the } 14 \text { th, whereas it is } \\
\text { the } 4 \text { th today.' } \\
\text { SEU } 2 \text { 'Decide not to select } \\
\text { the DAT as a Customer } \\
\text { Advisor has already } \\
\text { intervened and changed the } \\
\text { date to the 7th, whereas it is } \\
\text { the } 4 \text { th today.' } \\
\text { SEU } 3 \text { 'Identify the nature of } \\
\text { the DAT according to the } \\
\text { date selected by the previous } \\
\text { Customer Advisor and the } \\
\text { reason indicated.' } \\
\text { SEU } 4 \text { 'Decide not to select } \\
\text { the DAT as a Customer } \\
\text { Advisor has already } \\
\text { intervened and changed the } \\
\text { date to the } 7 \text { th, whereas it is } \\
\text { the } 4 \text { th today.' } \\
\text { SEU } 5 \text { 'Decide to select the } \\
\text { DAT as no date is indicated, } \\
\text { which means in theory that } \\
\text { this DAT may be immediately } \\
\text { processed, that we are not } \\
\text { waiting for something in } \\
\text { order to process it' }\end{array}$ & $\begin{array}{l}\text { Find a DAT that } \\
\text { she can process } \\
\text { immediately }\end{array}$ & & $\begin{array}{l}\text { Find a DAT that } \\
\text { can be processed }\end{array}$ & $\begin{array}{c}\text { Process the } \\
\text { case of a DAT } \\
\text { concerning an } \\
\text { invoice } \\
\text { adjustment }\end{array}$ \\
\hline $\begin{array}{l}\text { SEU } 6 \text { 'Understand if it } \\
\text { concerns a migrated } \\
\text { customer as their customer } \\
\text { number begins with ' } 5000 \text { ' } \\
\text { SEU } 7 \text { 'Access the customer } \\
\text { file using copy/paste of their } \\
\text { customer number' }\end{array}$ & $\begin{array}{l}\text { Access the } \\
\text { customer file in } \\
\text { SIMM as it } \\
\text { concerns a } \\
\text { migrated } \\
\text { customer }\end{array}$ & & $\begin{array}{l}\text { Understand the } \\
\text { precise purpose } \\
\text { of the request }\end{array}$ & \\
\hline
\end{tabular}

We produced reduced narratives for several cases concerning each stage in the processing of the request for the dual-fuel service. We therefore possessed reduced narratives regarding the point of the view of customer advisors processing the subscription stage (Stage 1 - Time 1), and of customer advisors processing the signed gas contract processing stage (Stage 2 - Time 2), etc.

Finally, each reduced narrative gave rise to the production of an analytical graph of the course of action, the aim of which was to understand the development of the construction of the course of action of the customer advisors by highlighting 1) the significant units of the course of action of each of the advisors distinguished according to the openings on which they were based at each instant and 2) the temporal arrangement of the different openings structuring the customer advisor's involvement. The comparison of all these graphs enabled us to generalize more broadly and identify 'typical' openings and significant structures, i.e. that are found in each of these modellings. For example, the opening entitled 'combine your activity with those of others' is found in the activity of each of the customer advisors involved in processing a stage of the request for the dual-fuel service. 


\subsubsection{From typical opening to object of the activity, and from typical significant structure to the emergence of instruments}

51 Combination with the instrumental approach commences from this stage onwards. Based on our knowledge of the typical dimensions of the activity of the customer advisors, we proceeded:

- From typical opening to the object of the activity: the instrumental approach 'consists in identifying objects of the activity, as well as invariant organizations of the activity (schemes and instruments) enabling the subject to act on these objects of the activity' (Bationo-Tillon, 2006, p. 314).

In studies on the theory of activity, including the instrumental approach, the objects of the activity of agents seem to be understood 'on the fly', as if they were created by the agent from nothing. Starting from a phenomenology of the human activity enabled us to overcome this impasse and identify objects of the activity as being anchored in a history in progress, which constitute the dynamic context for the agent.

The proximity between the notions of opening and object of the activity enabled us, based on our knowledge of the typical openings, to develop knowledge about the objects of the activity of the customer advisors, and thus examine the resources they use for the purpose of these objects, i.e. their instruments (Rabardel, 1995, 2005a, 2005b; Rabardel \& al, 2002; Folcher \& Rabardel, 2004a, 2004b; Rabardel \& Béguin, 2005). Hence, for example, the typical opening 'Articulate your activity with that of the other agents processing the request' becomes an object of the activity in the instrumental approach, and constitutes a starting point enabling us to identify the invariants serving this object.

- From typical significant structure to the hypothesis of the instrumented action scheme: typical significant structures express fundamental general components of the activity of the agents and correspond to a high degree of generalization. The typical character of these structures, through the notion of typicality, links directly to the instrumented action scheme concept in the instrumental approach. In effect, the typical character of significant structures contains two dimensions present in the schemes, namely regularity, invariance and similarity understood at a high level of generalization of the human activity. It is for this reason that we chose to begin with typical sequences in order to propose hypotheses of instrumented action schemes. Hence, for example, the typical sequences 'Transmit useful information for the subsequent processing of the request' and 'Leave information concerning the processing of the stage just processed' enable us to propose the hypothesis of the existence of a scheme concerning the transmission of information for those involved in processing the request at a later time.

- Finally, in order to complete the highlighting of the instruments of customer advisors, we examined the artefactual resources systematically employed with the identified scheme(s).

\subsubsection{Diachronic compilation: from the level of the stage to the level of the request processing process as a whole}

The third stage consisted in stepping back and accumulating the layers of instrumented activity of different temporalities. This meant working up from the level of each stage to the level of the processing of the request as a whole. This change in level was based on knowledge of the activity of the agents at each stage, and was necessary in order to reveal the continuity resulting from what the customer advisors implement at each stage to articulate their respective contributions. We thus linked knowledge of the instruments at each stage to the level of the processing of the request as a whole, to 
reveal and access the continuity supported by these instruments. Without this accumulation of layers of instrumented activity, carried out by the researcher, the transitional activities and instruments developed by the agents for the purpose of these activities would be more difficult to comprehend.

In effect, as shown in the study on travel, these transitional activities are not visible by tracking the objects of the activity. For example, regarding cross-sectional collective activity within the commercial process, we thus identified a recurrent opening in the activity of the customer advisors: 'Articulate your activity with those of others', which revealed consideration by customer advisors of the existence of a collective processing of the request, over and above the single processing of the stage incumbent on them. This typical opening, which we considered as an object of activity, is oriented towards the cross-sectional collective activity. Examination of the objects of the activity is not, however, sufficient to track the thread of the cross-sectional collective activity and its instruments. Bear in mind that this collective activity is based on the plotting of material left by other agents to reconstruct the history of the processing of the request up to this time, and on the transmission/archiving of information for those subsequently following up with this processing. While the object of the activity regarding the transmission/archiving is directly oriented towards the collective processing, this is not the case for the object of the activity regarding the plotting of material left by others. When leaving information for others, the customer advisor voluntarily articulate their contribution with that of the other person following them in the processing of the request, by leaving information not directly relevant for them but for the person taking over from them elsewhere and at a later time. This is not the case where the customer advisor takes over in processing the request. When plotting the traces left by others, the customer advisor is involved in processing the stage incumbent on them and is not aware that they are in the process of articulating their contribution with those preceding them. For the researcher, this meant examining the origin of the plotted material when customer advisors take over in the processing of a request. It is, in effect, this tracking of the 'trace' by the researcher that makes it possible to access the transitional dimensions of the activity, without which they would likely be missed.

\subsubsection{Cooperative transitional instruments, instruments of continuity in organizations}


Figure 4: Cooperative Transitional Instruments, instruments of temporal continuity at the heart of organizations.

Figure 4 : Les Instruments Transitionnels Coopératifs, instruments de la continuité au cœur des organisations

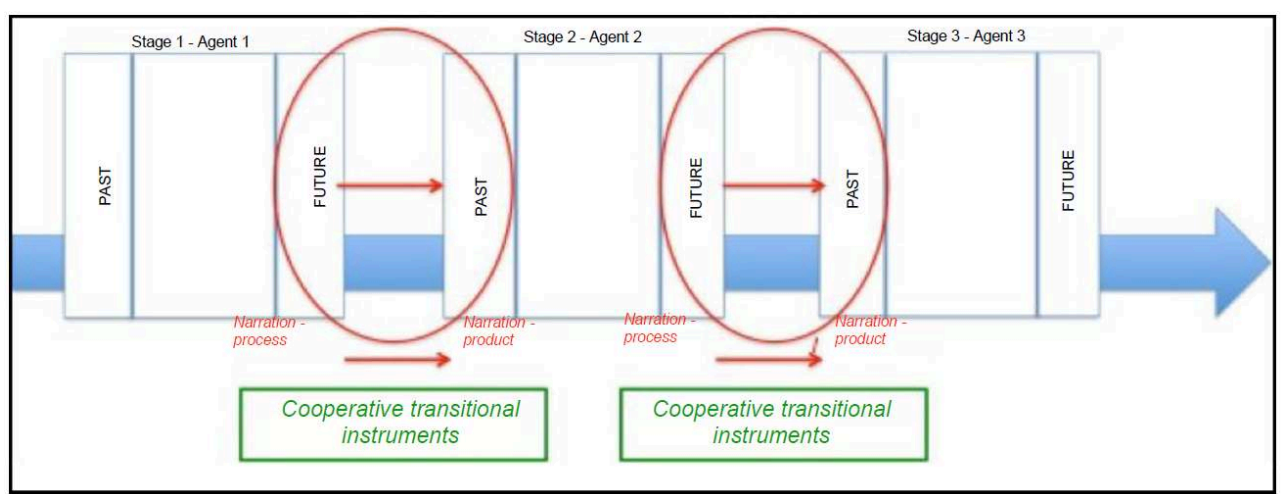

The instruments plotted and transmitted/archived are cooperative transitional instruments for the purpose of combining Past-Present-Future at each stage, as they make it possible for the agent processing the current stage of the request both to reconstruct the past dimensions by means of the plotting, and to anticipate the future processing by means of the transmission/archiving. They thus make possible the presentification of the past and the presentification of the future processing of a request for each agent involved in processing a stage of this request. If we leave this stage-by-stage perspective and broaden the focus to take an overview of the processing of the request, these instruments make possible a transition between the future of the processing of the request envisaged by agent 1 at $t$, and the past of this processing envisaged by agent 2 and $t+1$ (Fig. 4). They thus constitute instruments of temporal continuity at the heart of organizations.

In effect, they make possible the transition between a stage 1 at $t$ and a stage 2 at $t+1$, by maintaining a certain continuity. This continuity, contrary to the transitional instruments revealed by Bationo-Tillon (2006) regarding individual activity, cannot be a continuity of experience as the agent acting at the level of stage 1 at $t$ and the one acting at the level of stage 2 at $t+1$ are not the same. In other words, these instruments make it possible to maintain a certain continuity in the processing of the request, despite a discontinuity of the experience between each stage. This discontinuity of the experience between the different stages lies at the origin of the fact that the agents cannot rely on their personal memory. This is why, like historians, they implement a historical investigation activity, the aim of which is to reconstruct the past dimensions of the processing of the request.

Lastly, the polyvocal and poly-addressee nature of transitional instruments of travel narrators are reflected in the cooperative transitional instruments of the customer advisors. In effect, our research distinguished between transmission and archiving when it came for customer advisors to leave traces of their activity for other people in the information system. When this other person is known to the customer advisor, not personally but from the point of view of the following stage and associated job, the customer advisor 'transmits' the information they know to be of use for the following stage. When this next stage is not identified, and the customer advisor therefore has no idea of who will subsequently take over the processing of this request, they 'archive' the information they think may be useful for the future processing of the request. 


\subsection{Cross-fertilization between the instrumental approach and the course of action in addressing transitional phenomena}

57 Without the course of action, we would not have been able to grasp the phenomenological dimension of the activity, without which we would not have been able to grasp the semiological dimension, i.e. the meaning of the activity for the subject, without which we would not have been able to appreciate the transitional phenomena of the narrative activities; as the subjects forge deeper continuity for themselves. While this continuity may appear as external discontinuity for the outside observer, for the researcher, the aim is to understand the deeper forms of continuity.

Without the instrumental approach, we would not have been able to understand the material and instrumental dimension of the narrative activity as we were able to do. We would not have been able to accumulate episodes of instrumented activity to identify the transitional instruments at a diachronic level.

Without the conjunction of these two approaches, we would not have been able to appreciate the movements of fusion/dissociation, phenomena that enable subjects to cross boundaries. We would not have been able to interpret what emerges, reifies and refluidifies in the intertwining of worlds, which is what we were really seeking: in other words, we would have failed to grasp the developmental dynamics encapsulated in these transitional narrative activities.

\subsection{Different levels of transition and boundary crossing}

60 The comparison of these two research studies shows that the combination of the frameworks of the course of action and the instrumental approach makes it possible to perceive scales levels of transition.

61 Hence, in the sphere of travel narratives, transitions are perceived at the scale of the individual. The transitional instruments highlighted in this research are resources that the subject creates for the self in the making, enabling the creation of continuity for the subject in order to maintain a link with the travel experience while also being able to consider it as external to the self. The transitional instruments make it possible to think at the same time of narrative instruments that are by their nature different according to successive contexts: during their collection, the narrative activities are synchronous and tied up with a variety of other activities (meeting people, travelling around) and the narrative activities enable the narrator to extract himself from an immersive situation. On the other hand, they are at the forefront during the preparation of the narrative, where the narrator finds himself looking back over his materials to revisit his experience and construct a narrative. These transitional instruments reveal the diverse forms of activity at work within successive narrative activities as well as their successive reifications.

In the context of a commercial customer relationship process, transitions are perceived according to a cross-sectional collective framework, at the crossroads between the collective and organizational levels. In effect, the transitional instruments highlighted in this study are resources that make it possible to create continuity within the crosssectional collective activity and, in doing so, continuity within the processing of the customer request. These instruments bring together fragments of the technical and 
organizational system for the benefit of a collective activity that creates crosssectionality within organizations. The transitional approach thus makes it possible to access the level of the organization intrinsically, commencing with the individual and moving up to the organizational level. One of the next objectives of our research programme based on this approach is to apply it at the inter-organizational level, in the context of supply chains.

It is the combination of the two conceptual frameworks that enables us to reconstruct the semiological and structural continuity of instrumented developmental units of activities spread over different space times in the sphere of travel narratives, on the one hand, and in the context of a commercial customer relationship process, on the other hand. We qualify these developmental activities, which take place in a movement of duration and becoming, 'instrumented transitional activities'. From this point of view, the course of action enables us to analyse the continuous and discontinuous singular temporal course of transitional activities, while the instrumental approach enables us to cut up instrumented transitional activities in a structural sense. By adopting a diachronic and semiological unit of analyse that includes and makes it possible to contain all the heterogenous activities taking place in different space times, and by examining not only the succession of instrumented transitional activity sequences but also the succession of semiological activity sequences, which signal the same thing for the agents but in different time spaces, we are able to characterize a phenomenology of the transitional activities, in other worlds a phenomenology of the activities undergoing transformation according to a developmental process.

\section{Conclusion}

This paper explains how the articulation of the course of action and the instrumental approach made it possible to develop a transitional approach, focusing on the crossing of boundaries from an intrinsic point of view. This approach was based on two studies in ergonomics from contrasting fields of activity. These studies highlighted so-called transitional instruments, i.e. instruments that make it possible to maintain the continuity of an experience or process despite the discontinuity that characterizes the activities studied.

The transitional approach seeks to extricate itself from a top-down perspective and instead follow subjects' power to act, from their own genesis and the manner in which they cobble together transitional instruments to grow and deploy their narrative activity. Focusing on the capable subject (Rabardel, 2005) means respecting and encouraging the singular developmental paths of subjects and groups working collectively.

Throughout this article, we have implicitly presented the manner in which we reconciled the theoretical framework of the course of action developed by Theureau $(2004,2012)$ and the theoretical framework of the instrumental approach developed by Rabardel $(1995,2005)$ to obtain the means of tracking the transitional phenomena that interest us like a photographer, by varying the focus so as keep sight of the different scales/degree of granularity involved in the development of a subject in the making or a cross-sectional working group in order to cross the boundaries of an organization set up by the information system. We qualify these boundary crossing activities as 'transitional activities'. Hence, in our opinion, the necessity of taking a transitional 
approach in order to support the development of organizations. The foundations of such an approach are both epistemic and pragmatic:

1. On the epistemic level, this means identifying the activity systems and people working at the boundaries of these activity systems in order to analyse the transitional activity, i.e. the manner in which these people creation continuity to hold heterogenous systems together for themselves, first of all, which then enables them to connect worlds. It is this individual and collective activity that consists in forging continuity and articulating several activity systems that we qualify as transitional. Analysis of the activity of boundary people makes it possible to understand the heterogenous reasonings they come up against, as well as the strategies and resources developed to overcome these sometimes contradictory reasonings and hold them together in order to cross the organizational boundaries.

In more specific terms, the transitional approach seeks to understand the manner in which people cross boundaries, forging continuity between individual, collective, organizational and inter-organizational levels, whether or not they occupy positions explicitly requiring them to cross such boundaries. In organizations, certain functions are in effect designed to combine and coordinate different worlds. This is the case, for example, of case managers (Ennuyer, 2012) in the field of healthcare, and other professions whose core purpose is coordination. These people may be extrinsically designated as boundary people, which is not the case for travellers and customer advisors. In effect, it is important to look at boundary crossings by people whose position does not explicitly require them to do so, but who perform these crossings as part of ordinary transitional activities.

2. At the pragmatic level, we should specify that from a transitional point of view, the ergonomist necessarily becomes a boundary person; by contributing through their analysis to the identification of subjects' boundary crossing strategies, they in turn contribute to encouraging the recomposition of fragmented units of activities by means of reflectivity mechanisms on the one hand (self-confrontation interviews) and by leading and codesigning working groups including agents from a variety of contradictory activity systems, on the other (Folcher, 2015).

Apart from transitional instruments, could the transitional approach be used to examine, support and jointly design transitional systems within organizations? As Pastré (2011) rightly says, with the development of an ontology and epistemology of the capable subject, the focus is shifting; whereas theories of activity are based on a distinction between the subject's sphere and the sphere of the object of the activity, the aim is now to decipher a link between the subjects and the world. The subject is considered as engaging with the world to transform it and transform themselves. The transitional approach proposes to examine what happens over the course of transitional episodes in which the experience of the subject or a group of subjects is reorganized via a movement of union and separation of the subject and of the world. We argue that development can take place at different levels during the transitional episode. In order words, the transitional approach examines more precisely the intrinsic reconfigurations that take place in the relationship between local and global scales of activity. But what happens in this movement of becoming? How can we hold these heterogenous worlds together? How can we reconstitute fragmented units of activity, broken apart by organizational boundaries? How can we support and decipher the instrumental geneses (Rabardel, 1995), identity geneses (Pastré, 2005) and professional geneses (Béguin, 2005)? These are the questions opened up by the conceptual and empirical work seeking to shed light on the topic of organizational geneses (Folcher, Bationo, 2018). 


\section{BIBLIOGRAPHY}

Akkerman, S., \& Bakker, A. (2011). Boundary Crossing and Boundary Objects. Review of Educational Research, 81(2), 132-169.

Bationo Tillon, A. (2006). Pratiques des activités narratives instrumentées : Une analyse diachronique et structuro-fonctionnelle en amont de la conception. Doctorat d'ergonomie, Saint Denis : Université de Paris 8.

Bationo-Tillon, A. (2017). Chemin transitionnel - ouverture pluridisciplinaire pour une ergonomie développementale. Habilitation à diriger des recherches, Université Paris 8.

Bationo-Tillon, A., Folcher, V., \& Rabardel, P. (2010). Les instruments transitionnels : une proposition pour étudier la diachronie des activités narratives. Activités [En ligne], 7-2.

Bationo-Tillon, A., \& Rabardel, P. (2015). L'approche instrumentale : conceptualiser et concevoir pour le développement. In F. Decortis (Ed.), L'ergonomie orientée enfants. Concevoir pour le développement (pp. 109-145). Paris : PUF.

Béguin (2005) Concevoir pour les genèses professionnelles ; p.31-52. In P. Rabardel \& P. Pastré (Eds.), Modèles du sujet pour la conception (pp. 231-260). Toulouse : Octarès.

Bouvier, N. (1992). Usage du monde. Paris : Payot.

Brulhart, F., \& Favoreu, C. (2006). Le lien contrôle-confiance-performance dans les relations de partenariat logistique inter-firmes. Finance Contrôle Stratégie, 9(5), 59-96.

Bruner, J.-S. (1990). Acts of meanings. Cambridge : Havard University Press.

Christin, R. (2000). L'imaginaire voyageur ou l'expérience exotique. Paris : Éditions L'Harmattan.

Engestrom, Y. (2001). Expansive learning at work: Toward an activity theoretical reconceptualization. Journal of Education and Work, 14, 133-156.

Ennuyer, B. (2012). Un regard critique sur les « gestionnaires de cas », dernière « mode » de la coordination imposée par le plan Alzheimer. Gérontologie et société, 35(142), 205-213.

Fawcett, S., \& Magnan, G. (2002). The rhetoric and reality of supply chain integration. International Journal of Physical Distribution \& Logistics Management, 32(5), 339-361.

Folcher V. (2015). Concevoir pour et dans l'usage, la maitrise d'usage en conduite de projet, Revue des Interactions Humaines Médiatisées, RIHM, 16(1), 39-60.

Folcher V., \& Bationo-Tillon A. (2018). Approche instrumentale dans l'intervention ergonomique. Congrès de la SELF 2018. Bordeaux.

Folcher, V., \& Rabardel, P. (2004). Hommes, Artefacts, Activités : perspective instrumentale. In P. Falzon (Ed.), Ergonomie (pp. 251-268). Paris : PUF.

Hutchins, E. (1995). Cognition in the wild. Cambridge : MIT Press, 381 p.

Maturana, H., \& Varela, F. (1980). Autopoiesis and Cognition. Dordrecht : Reidel.

Motté, F., \& Haradji, Y. (2010). Construire la relation de service en considérant l'activité humaine dans ses dimensions individuelles et collectives. In G. Valléry, M.-C. Le Port, \& M. Zouinar (Eds.), Ergonomie, conception de produits et services médiatisés (pp. 11-35). Paris : PUF.

Motté, F., \& Poret, C. (2018). La Simulation Réflexive Transvserse : une méthode pour ancrer l'activité humaine au cœur de la performance de l'entreprise. Activités, 15(1). 
Pastré, P. (2005) Genèse et identité. In P. Rabardel \& P. Pastré (Eds.), Modèles du sujet pour la conception (pp. 231-260). Toulouse : Octarès.

Pastré, P. (2011). La didactique professionnelle. Approche anthropologique du développement des adultes. Paris : PUF.

Poret, C. (2015). Concevoir pour le Pouvoir d'agir ensemble d'un collectif transverse. Le cas de la relation de service dans le domaine commercial. Thèse de doctorat, Université Paris VIII.

Poret, C., Folcher, V., Motté, F., \& Haradji, Y. (2016). Concevoir pour le Pouvoir d'agir ensemble au sein des organisations : le cas d'un processus commercial. Activités, 13(2).

Rabardel, P. (1995). Les Hommes et les technologies. Paris : Armand Colin.

Rabardel, P. (2001). Instrument mediated activity in situations. In A. Blandford \&

P. Vanderdonckt (Eds.), People and computers XV Interactions without frontiers (pp. 17-30). Verlag : Springer.

Rabardel, P. (2005). Instrument subjectif et développement du pouvoir d'agir. In P. Rabardel, \& P. Pastré (Eds.), Modèles du sujet pour la conception. Dialectiques activités développement (pp. 11-29). Toulouse : Octarès.

Rabardel, P., \& Béguin, P. (2005). Instrument mediated activity: from subject development to anthropocentric design. Theoretical Issues in Ergonomics Science, 6(5), 429-461.

Rabardel, P., \& Pastré, P. (2005). Modèles du sujet pour la conception. Dialectiques activités développement. Toulouse : Octarès.

Rix, G., \& Biache, M-J. (2004). Enregistrement en perspective subjective située et entretien en resitu subjectif : une méthodologie de constitution de l'expérience. Intellectica, n 38, 363-396.

Suchman, L. (1987). Plans and Situated Actions - The Problem of Human/Machine Communication. New York : Cambridge university press.

Theureau, J. (2004). Le cours d'action : méthode élémentaire. Toulouse : Octarès.

Theureau, J. (2006). Le cours d'action : méthode développée. Toulouse : Octarès.

Vermersch, P. (1994). L'entretien d'explicitation. Issy Les moulineaux : ESF.

Wenger, E. (1998). Communities of practice, learning, meaning and identity. Cambridge, UK :

Cambridge University Press.

Winnicott, D.-W. (1971). Objet transitionnels et phénomènes transitionnels, Jeu et réalité. Paris : Gallimard.

\section{NOTES}

1. By subject's worlds, we define the term "world" according to the intrinsic logic of the subjects. Subjects' world or worlds correspond to subject-centred space times. The plural nature of subject worlds means the subject's multiple ways of being in the world.

2. Only the first three stages are common to both studies. The fourth stage is specific to the study on travellers.

3. We agreed with the participants of the study and a third party taking part in the polar expedition that video recordings of the narrative activity would be made at appropriate times (during the expedition, in the evenings in the tent and on their return when the narrators sat down to prepare their narratives). 
4. Each S.E.U. Is based on a so-called hexadic sign insofar as it links six components in a precise relational structure (Involvement-Potential Actuality-Referential-Representamen-UseInterpretant), which are assumed to summarize the processes at work in the significant elementary unit for the agent.

5. tetradic sign: the tetradic sign emerged prior to the hexadic sign in Theureau's theoretical development and comprises four components (object, representamen, interpretant and use)

6. Term borrowed from the language of course of action approach, meaning what makes a sign for the agent. The Representamen (R) is an element of the hexadic sign that is similar to the notion of 'disruption' for Varela. In the course of action approach, Representamens are disruptions that give rise to prereflective conscience.

7. In the course of action approach, the openings constitute structural dimensions of the agent's Involvement in the situation, by opening a horizon of expectation. All openings created in the past but not yet closed constitute the system of openings at a given moment $t$, a framework for interpreting disturbances or events for the agent.

\section{ABSTRACTS}

In this paper, we propose to address the question of possible conceptual ways of thinking about organizations in the making. We begin by introducing the concept of borders, which seems heuristic to us, to define development as crossing borders. We then propose to consider the crossing boundary from an intrinsic point of view by adopting a transitional prism. To adress these transitional phenomena, we articulate two conceptual frameworks of ergonomics: the course of action and the instrumental approach. Through two contrasting researches from the point of view of the fields of activity (narrations of travel and a process of treatment of the customer demand in the field of energy), we confront the ways to hybridize these two theoretical frameworks conceptually, methodologically and empirically. We highlight what results from this hybridization: some transitional instruments that carry continuity on different scales. Finally, we discuss the perspectives opened by a transitional approach to thinking about organizational genesis.

Nous proposons au sein de cet article d'aborder la question des voies conceptuelles possibles pour penser les organisations en devenir. Nous commencerons par introduire le concept de frontière qui nous semble heuristique pour définir le développement des organisations comme franchissement de frontières. Nous proposerons dans un second temps d'aborder le franchissement de frontière d'un point de vue intrinsèque à travers le prisme transitionnel. Pour rendre compte de ces phénomènes transitionnels, nous avons hybridé deux cadres conceptuels de l'ergonomie que sont le cours d'action et l'approche instrumentale. À travers deux recherches contrastées du point de vue des domaines d'activité (narrations de voyage et un processus de traitement de la demande client dans le champ de l'énergie), nous confronterons la manière dont il est possible d'hybrider ces deux cadres théoriques conceptuellement, méthodologiquement et empiriquement. Nous mettrons en évidence ce qui résulte de cette hybridation : des instruments dits transitionnels porteurs de continuité à différentes échelles. Enfin, nous évoquerons les perspectives ouvertes par une approche transitionnelle pour penser les genèses organisationnelles. 
INDEX

Mots-clés: approche transitionnelle, développement, frontières, genèse organisationnelle Keywords: transitional approach, development, organizational genesis, boundaries

\section{AUTHORS}

\section{ANNE BATIONO-TILLON}

Université Paris 8/Paragraphe laboratory/C3U team, 2 rue de la liberté, 93526 Saint-Denis Cedex anne.bationo-tillon@univ-paris8.fr

\section{CÉLINE PORET}

Nuclear Safety and Radioprotection Institute (IRSN) ; Human and Social Sciences Laboratory (LSHS), B.P. 17 - 92262 Fontenay-aux-Roses Cedex celine.poret@irsn.fr

\section{VIVIANE FOLCHER}

Université Paris 8/Paragraphe laboratory/CITU team, 2 rue de la liberté, 93526 Saint-Denis Cedex

viviane.folcher@univ-paris8.fr 